\title{
PREDICTION AND EXPERIMENTAL CHARACTERIZATION OF THE MOLECULAR ARCHITECTURE OF FRP AND ATRP SYNTHESIZED POLYACRYLATE NETWORKS
}

\author{
Rolando C. S. Dias, LSRE-Instituto Politécnico de Bragança \\ Quinta de Santa Apolónia, Bragança, Trás-os-Montes, 5300, Portugal \\ T: +351273303088, F: +351273313051, rdias@ipb.pt \\ Miguel A.D. Gonçalves, LSRE-Instituto Politécnico de Bragança \\ Mário Rui P.F.N. Costa, LSRE-Faculdade de Engenharia da Universidade do Porto
}

Following recent research works [1,2], this work reports additional experimental and modeling studies concerning the conventional (FRP) and atom transfer radical polymerization (ATRP) of acrylate/diacrylate monomers. In the framework of a recently developed general approach [3-5], kinetic models including crosslinking reactions and branching by chain transfer to polymer are discussed for FRP and ATRP polymerization systems. Besides MWD, the prediction of the $z$-average radius of gyration is shown to be possible for these non-linear polymers.

A set of experiments was performed at $1 \mathrm{~L}$ scale in a batch reactor using $n$-butyl acrylate (BA) or methyl acrylate (MA) as monovinyl monomers and 1,4-Butanediol diacrylate (BDDA), 1,6-Hexanediol diacrylate (HDDA) or bisphenol A ethoxylate diacrylate (BEDA) as crosslinkers. In FRP experiments, AIBN was used as initiator and ATRP polymerizations were initiated by ethyl 2-bromopropionate (EbrP) and mediated by $\mathrm{CuBr}$ using PMDETA $\left(N, N, N^{\prime}, N^{\prime \prime}, N^{\prime \prime}-\right.$ pentamethyldiethylenetriamine) as ligant.

Polymerizations were carried out in solution at $\mathrm{T}=60^{\circ} \mathrm{C}$ at different dilutions ( 15 to $56 \%$ volumetric fraction of monomer) using toluene, anisole and DMF as solvents. Products formed at different polymerization times were analyzed by SEC/RI/MALLS yielding average MW, MWD, $z$-average radius of gyration and monomer conversion.

Important differences in the molecular architecture of FRP and ATRP polyacrylate networks were identified and is shown that huge errors can result from the interpretation of chromatograms of these networks using linear calibrations. Comparison of experimental results with predictions put into evidence the important effect of intramolecular cyclizations at all dilutions, even with ATRP polymerizations.

\section{References:}

[1] Gao, H., Min, K., Matyjaszewski, K., 2007, Macromolecules, 40, 7763.

[2] Gao, H., Li, W., Matyjaszewski, K., 2008, Macromolecules, 41, 2335.

[3] Costa, M.R.P.F.N., Dias, R.C.S., 2005, Chem. Eng. Sci., 60, 423.

[4] Dias, R.C.S., Costa, M.R.P.F.N., 2006, Polymer, 47, 6895.

[5] Costa, M.R.P.F.N., Dias, R.C.S., 2007, Polymer, 48, 1785. 